\title{
Factors Affecting SMEs' Intention to Adopt a Mobile Travel Application based on the Unified Theory of Acceptance and Use of Technology (UTAUT-2)
}

\author{
Kritcha Yawised ${ }^{1 *}$, Darlin Apasrawirote ${ }^{1}$, Maneerut Chatrangsan ${ }^{1}$, Paisarn Muneesawang ${ }^{2}$ \\ ${ }^{I}$ Department of Business Administration, Faculty of Business, Economics and Communications (BEC), Naresuan University, Thailand \\ ${ }^{2}$ Department of Electrical \& Computer Engineering, Faculty of Engineering, Naresuan University, Thailand
}

\begin{abstract}
This study is part of a government research project which aims to synthesise the current evidence on the factors affecting the intention of mobile application adoption called 'Tripper Notifier Application' (TNA) for the hospitality and tourism industrial sector in Thailand. The focus is on small and medium enterprises (SMEs), which emphasize restaurants, hotels, and attraction sites. The present article examines various factors influencing the intention to use such applications by employing the Unified Theory of Acceptance and Use of Technology 2 (UTAUT-2) as the theoretical underpinning of this research paradigm. Using 84 selected research papers in Scopus published between 2020 and 2022, A thematic analysis incorporating a grounded theory approach to systematically generate themes was conducted, and the findings found three main themes, including business transformation capabilities (BTC), digital transformation capabilities (DTC), and personal innovativeness (PI), as an extension of UTAUT-2 as mediator and moderator variables. To this end, the study fills the research gaps and extends the UTAUT-2 framework by including an initiative of twelve inside attributes-based lines, including performance expectancy, effort expectancy, social influence, facilitating conditions, hedonic motivation, price value, habit behavior, behavioral intention, and use behavior, together with three moderators: age, gender, and experience. Finally, the context dimensions of the UTAUT-2 extensions were mapped to highlight all the constructs of the TNA adoption framework for future research directions. The novel contribution of this study is to fill the gap with both theoretical and practical knowledge. On the theoretical level, this study constitutes constructs based on UTAUT-2 theory as a research-based setting to fill a gap in research. On the practical level, it provides insights and information about new capabilities that SME owners, managers, and practitioners should consider in order to differentiate their own capabilities.
\end{abstract}

\section{Keywords:}

Travel Mobile Application;

COVID-19;

Business Transformation Capabilities; Digital Transformation Capabilities; DTC; BTC;

Service Sector;

UTAUT-2;

SMEs.

\section{Article History:}

Received: $05 \quad$ September 2021

Revised: $11 \quad$ January 2022

Accepted: $\quad 20 \quad$ January 2022

Published: $01 \quad$ February 2022

\section{1- Introduction}

The emergence of mobile applications, which have linked and empowered users, has posed a challenge to the fundamentals of how individuals and businesses communicate over the Internet. Businesses are increasingly incorporating and integrating the phenomena of mobile applications into their established business models. For example, fast distribution of advertising and promotion messages to existing customers and prospects helps with the speed of dissemination and improves effect at a lower cost than traditional marketing channels. The fact that this has ramifications

\footnotetext{
*CONTACT: kritchay@ nu.ac.th
}

DOI: http://dx.doi.org/10.28991/esj-2021-SP1-014

(C) 2020 by the authors. Licensee ESJ, Italy. This is an open access article under the terms and conditions of the Creative Commons Attribution (CC-BY) license (https://creativecommons.org/licenses/by/4.0/). 
for businesses is obvious to business owners-managers who witness their consumers' quick adoption and use of mobile application platforms. Recent advancements and changes in such technology, such as the establishment and expansion of online communities, have created a situation that might lead to new types of business-customer relationships. This, along with the broad use of mobile and smart phone applications that are linked with customer-centric management strategies, results in a fast-rising demand for businesses to engage socially with their consumers, prompting the creation of strategic mobile application methods.

Within the wider context of SM initiatives, particularly the way SMEs engage in such initiatives, it appears to differ. As a result, it's critical to have a clear picture of mobile app usage and engagement in practice, as well as to identify critical factors and requirements that influenced the adoption of such initiatives. According to the Ministry of Industry of Thailand, SMEs are classified based on the number of workers and fixed capital, excluding land and assets, as of 2002. As such, this research focuses on the service industries. A small business is defined as one with fewer than 30 workers and a fixed capital of less than THB 30 million (1 million USD). A medium enterprise is defined as a company with 31 to 100 workers and a fixed capital of less than THB 100 million (3 million USD) (OECD, 2020). When Coronavirus Disease 19 (COVID-19) began early in 2020, it had a significant negative impact on a variety of industrial sectors, particularly service and tourism industries, resulting in economic recessions in a number of developing nations. Developments in consumer behavior, as well as the unpredictability of scientific and technical advancements, exacerbate the unanticipated changes that force many SMEs to struggle to provide effective services to their consumers through traditional business channels. As a result, sustainability and digitalization involvement should be prioritized in new SME plans. Despite the fact that e-commerce transactions in Thailand are rising all the time, Thai SMEs have yet to properly incorporate digital technology into their business strategies. Digital adoption is difficult due to a lack of digital knowledge and abilities. According to previous research studies, the lack of time and associated expertise, the absence of top management support and clear-cut practical strategies, and the unpredictability of technical developments are all impediments to mobile application platforms and technology adoption.

From 2019 to 2022, many Thai SMEs located in rural regions were hit by the pandemic and an annually occurring flooding disaster, resulting in a dramatic drop in the number of domestic and international visitors. TNA was developed as an innovative application to foster the tourism sector and as a stimulus package to support SMEs in confronting hazards. This research is part of a project funded by the Thailand Science Research and Innovation (TSRI) governance to design and build a travel mobile application called 'Tripper Notifier Application (TNA)' for usage by both SMEs and visitors (tourists). It is research in progress. This project is based on the Thai government's tourism stimulus schemes, which are domestic travel stimulation packages that focus on restaurants, daily rental accommodation, and local hotels as well as important tourist attraction locations. TNA may be registered by both business owners and visitors using their smartphones. Local SME owners must register themselves as well as any information about their products and services (e.g., turn on business opening hours, daily promotions, and offers). TNA would attract visitors (or any users who have already downloaded and registered) by displaying a pop-up screen that would advise and alert them when they are nearing their destination. This alerts tourists and visitors who have never visited such a location before, including if nearby restaurants, hotels, and tourist attractions are now open. Also, despite the growing evidence that digital technologies can serve as a basis for business digital tools, there is a small amount of anecdotal evidence focusing on research outcomes or even determinant factors, especially in the context of emerging markets and developing countries such as Thailand. The investigation of antecedent constructs influencing SME owners, managers, and practitioners' perceptions towards the adoption of such an initiative is required.

In regards to mobile applications, previous research has investigated mobile applications in various tourism and hospitality industries using a variety of theories, such as travel application booking using the Theory of Planned Behavior (TPB) [1] and smart hotel by using the Technology Acceptance Model (TAM) [2]. Other studies have used the UTAUT as a research model regarding the application of facial recognition systems (FRS) in quick-service restaurants [3]. More research is therefore needed because relatively few studies have investigated mobile app adoption in the context of restaurant, hotel, and attraction search and notification, particularly employing UTAUT-2 as a theoretical framework during the COVID-19 pandemic between 2020 and 2022. Consequently, UTAUT-2 is the theoretical framework used in this research, and the objective will be achieved through the following steps:

- To explore the mediator and moderator variables from the process of systematically reviewing and synthesizing current literature during the COVID-19 pandemic between 2020 and 2022,

- To integrate the mediator and moderator variables into the UTAUT-2 model and explain the conceptualization and relationship between such constructs,

- To develop a theoretical framework and hypotheses for future research directions.

To this end, this article presents a new theoretical model to explain factor affecting SME's intention to adopt a mobile travel application called "Tripper Notifier" in Thailand and develops mediator and moderator variables that affect their intentions. Specifically, the conceptualizing and framing of the present study, coupled with the types of theoretical and 
conceptual foundations that may have been used to investigate components of work for future research, the theoretical frameworks and the construction of each researched article were also analyzed. The outputs of the sources were categorized and examined, and the relationship between predominant constructs in relation to the intention of mobile application adoption was presented.

The following is a breakdown of the structure of this research paper. The second section discusses the suggested research paradigm and hypotheses established, as well as reviews relevant literature. The study design, data collection procedure, analysis, and synthesis process are all included in the third component in order to develop themes and recommend constructions. The findings of the investigation and the proposed theoretical framework are provided in section four. Finally, sections five and six give the discussion and conclusions, as well as the study's limitations and future research directions.

\section{2- Literature Review and Theoretical Background}

The present study employed a combination of systematic review and thematic themes analysis of the relevant and related issues method, which is the underpinning of the UTAUT-2 based theory [4], in Scopus databases from January 2020 to January 2022. This study began examining the distribution of papers with a specific focus related to the intention of mobile application adoption based on both perspectives of SME owners and managers (i.e., restaurants, hotels, and tourist attraction sites) and travelers (tourists and visitors). The present study intends to utilize UTAUT-2 constructs and extend its moderators coupled with adding mediators to describe the phenomenon and cause of the change of behavior intention when the COVID-19 has become a buzzword and side effect of entire business sectors, leading to the change of mindsets during the COVID-19 lockdown in 2020.

\section{2-1-Mobile Application Implication in Business Context}

Numerous and rigorous studies on technology adoption and proposed acceptance models in the business context are being conducted. Mobile applications and smart devices on the cutting edge of technology have been well researched, providing an abundance of theoretical and empirical work. The study of mobile application adoption is being conducted in order to fill a gap in the field of interest. Specifically, over the last decade, the applications of food delivery service, hotel and flight booking, and travel applications streamlined with tourist attraction suggestions for people on vacation have been introduced [5,6]. Previous research suggests that most mobile applications downloaded by smart phone users could not be equally beneficial to all business sizes and sectors due to different factors stemming from business operations. Yet, COVID-19 appears to have accelerated technological adoption and innovation, including digital technologies and automation in businesses where such approaches were not previously prevalent. Businesses have accelerated the digitization of their customer and supply-chain interactions as well as their internal operations. Particularly, according to the Digital 2021 Global Overview [7], Thai users will have the highest level of internet access in 2021 (i.e., 85\% of the population using mobile applications for search engines, especially for traveling, accommodation, and food consumption, representing 3.38 billion US dollars [7]) compared to global activity (searching engines online for products and services at $81.5 \%$ and visiting online retail sites at $90.4 \%$ ), and Thai consumers will be among the world's heaviest users of SM; specifically, in 2021, the number of internet users in Thailand increased by 3.4 million (+7.4\%) between 2020 and 2021 (48.59 million internet users, 90.66 million smartphone device connections, and 55.00 million SM users).

Additionally, the existence of mobile applications for Thailand's domestic travel (e.g., Traveloka, Hotel Booking App, Klook, Wongnai, AirVisual, Amazing Thailand, and so forth) focused mostly on the planning of trips of visitors, such as booking flight tickets, accommodations, currency exchanges, translators, and presenting images and videos of the destination that would be an attractive and famous landmark for overseas visitors. In contrast, SME businesses and outlets from lesser-known regions (among such outlets were both on-premise food service businesses such as restaurants, bars, and cafes) (hotels, motels, and rental daily room services) have not been introduced and/or mentioned for urban people and/or overseas visitors. TNA is established as a push notification, presenting a screen that pops up on a mobile device to notify visitors when the establishment of local SME businesses is nearby. Nevertheless, although both researchers and practitioners argue that investments in mobile digital technologies should be a strategic imperative for SMEs [8], understanding the critical factors behind the adoption and acceptance of technology is also necessary. Adoption of TNA is not only about technology; it is all about determining if the company is prepared for impending organizational changes in the digital age. In particular, studies on factors influencing the adoption of mobile applications by SMEs located in rural regions could have changed business owners' perspectives towards the business ecosystem in terms of adaptability, resilience, and organizational agility.

\section{2-2- The Unified Theory of Acceptance and Use of Technology 2 (UTAUT2)}

Venkatesh et al. (2003) proposed the UTAUT model to provide a unified view of user technology acceptance, grounded on eight prominent models in the technology acceptance field. A unified theory identifies four determinants 
of user acceptance and usage behavior: (i) Performance Expectancy (PE), (ii) Effort Expectancy (EE), (iii) Social Influence (SI), and (iv) Facilitating Conditions (FC) [9]. Although the UTAUT model could achieve successful outcomes in the adoption processes of a variety of IS/IT technologies in different cultural settings, it does not show a notable difference with TAM [10] and TPB [11] in terms of revealing factors of impulsive behavior after the COVID19 pandemic phenomenon. Furthermore, precedents of UTAUT-based mobile application research have been well conducted with a wide range of subjects including mobile commerce [12], mobile banking and payment [13, 14], ehealth and hospitals $[15,16]$, and some restaurants and hotels $[3,17,18]$. The potential mechanisms as moderators and mediators of intervention effects within are not included in the explanatory variables that explain intentions to use mobile applications. Venkatesh et al. (2012) enhanced the UTAUT theory by introducing (v) Hedonic Motivation (HM), (vi) Price Value (PV), and (vii) Habit Behavior (HB) in addition to the original UTAUT, while all such constructs impact on behavior intention, especially FC and HB, which directly influence the actual use. With this addition, UTAUT-2 has evolved into a more robust forecasting system [4]. UTAUT-2's utility as a technology adoption framework has been clearly shown.

However, this study argues that the new attributes that could enhance SME survival by unlocking legacy business models led to a climate of transition during COVID-19, particularly among Asian SMEs, which are well placed to adapt and lead global adaptation and mitigation efforts, resulting in gradual progress on sustainability. This implied that SMEs are currently in the process of transition. Thus, this study considers Business Transition Capability (BTC) and Digital Transformation Capabilities (DTC) as new mechanism dimensions that could directly mediate positive actual use of TNA; on the other hand, such a relationship could be moderated by Innovative Personality (IP) also.

The explanatory variables that explain intentions to use TNA, such as PE, EE, SI, FC, HM, PV, HB, together with new demographic attributes IP as moderators apart from the existing moderators (e.g. age, gender, and experience) and the new construct of mediators BTC and DTC to examine Behavior Intention (BI) to use and Use Behavior (UB), are all included in the UTAUT-2 theoretical framework used in this study. The UTAUT-2 has been shown to have predictive importance in the adoption of theories, and it provides a suitable setting for a better understanding of TNA adoption intentions during the COVID-19 in the context of SME owners and managers.

\section{Definition of Constructs in the UTAUT-2}

According to Venkatesh et al. (2012), UTAUT-2 describes twelve constructs, (in)directly influencing Use Behavior (UB). A central, mediating, construct in the model is Behavioral Intention (BI). There are four predictors for BI, including: Performance Expectancy (PE) is 'the degree to which an individual believes that using the Expectancy system will help them to attain gains in job performance'. PE is a strong predictor for BI, moderated by gender and age. This effect is stronger for men and younger workers. Effort Expectancy (EE) is defined as 'the degree of ease of use associated with the system'. EE is moderated by gender, age, and experience for predicting BI. This effect is stronger for women, particularly younger women, at early stages of experience. Social Influence (SI) is defined as 'the degree to which an individual perceives that important others believe he or she should use the new system'. SI is moderated by gender, age, voluntariness, and experience. This effect is stronger for women and older people. When use is mandatory, social influence has been found to be relevant only in the early stages of individual experience with the technology. Its influence decreases over time and becomes non-significant. Facilitating Conditions (FC) directly influence UB and are defined as 'the degree to which an individual believes that an organizational and technical infrastructure exists to support use of the system'. FC is found to be stronger for older workers, particularly with increasing experience. Venkatesh et al. (2012) also defined Hedonic Motivation (HM) as the fun or enjoyment obtained from utilizing a technology. This construct has been found to have a significant influence in deciding technological acceptability and use. Following this, previous research has postulated and evaluated the beneficial impact of perceived pleasure on mobile internet uptake and mobile banking [3,9]. Price Value (PV) refers to the consumer's cognitive tradeoff between perceived advantages and the monetary cost of such benefits. Once this TNA application is free of charge, this variable is irrelevant to the model. However, from SME owners' perspectives, price-saving orientation is considerable, regardless of the economic benefits that are obtained. In other words, SMEs can save money in terms of brand awareness promotion, time, and costs associated with staff training. As a result of their education, people are prone to doing automatic actions as a result of their education [4]. It refers to a self-reported view of a habitual behavioral pattern that happens without conscious awareness. Venkatesh et al. (2012) discovered two important connections: habit-intentions to use and habit-usage. The original constructs of UTAUT-2 are shown in Figure 1.

\section{2-3- The Implications of Business and Digital transition}

The present study proposes that the 'Business Transition' attribute be defined as how to transition people, teams, and organizational culture, as well as business operating procedures. In this sense, initial business capabilities could be transformed to fully integrate sustainability at every step of the business process by using digital technologies to bridge a gap and guide business owners-managers on how to create such new capabilities that are not imitable by competitors. In SMEs, digital technologies will mark the beginnings of a new business change. Previous studies have examined the 
effects of digital technologies on tourism businesses with the intention of presenting a new perspective for SME ownersmanagers to adopt a new cutting edge of technologies such as proposing technological devices, techniques, and achievements that employ the most current and high-level IT developments [19]. For instance, the ability of big data or infrastructure scalability to handle unstructured marketing data and analytics machine systems to develop new individual or profile data for marketing reasons (predictive analysis) [20]. Such qualities would be more useful in handling big data in the tourism and hospitality sectors, which are characterized by great volume, velocity, and diversity, such as booking flight tickets, daily accommodation rentals, and searching for historical local restaurants and cafes. In addition, in a hyper-connected future, the use of Virtual Reality (VR) [21], Augmented Reality (AR) [19], smart voice search engines/voice assistants for traveling [22], data science (analytics) [23], deep/machine learning [24, 25], and the Internet of Things (IoTs) [26-28], Internet of Vehicle (IoV) technology [29] combined with block chain technology would create a data journey with multiple connected intermediary goals that aspires to ubiquitous optimization across processes, divisions, and the business ecosystem in a hyper-connected future [30, 31]. For example, both IoTs and IoV can connect and communicate with various devices in order to create a personalized customer experience. Prior smart tourism research involved IoTs and IoV facets in order to improve the efficiency of rural tourism [32], such as accommodations [26], restaurants [33]. This necessitates the involvement of company owner managers in capability development, organizing the resource portfolio utilizing specific methods, and requiring creative and inventive operational and management abilities. All of the above-mentioned investigations have aided firms in progressing and gaining widespread support for digital technology adoption.

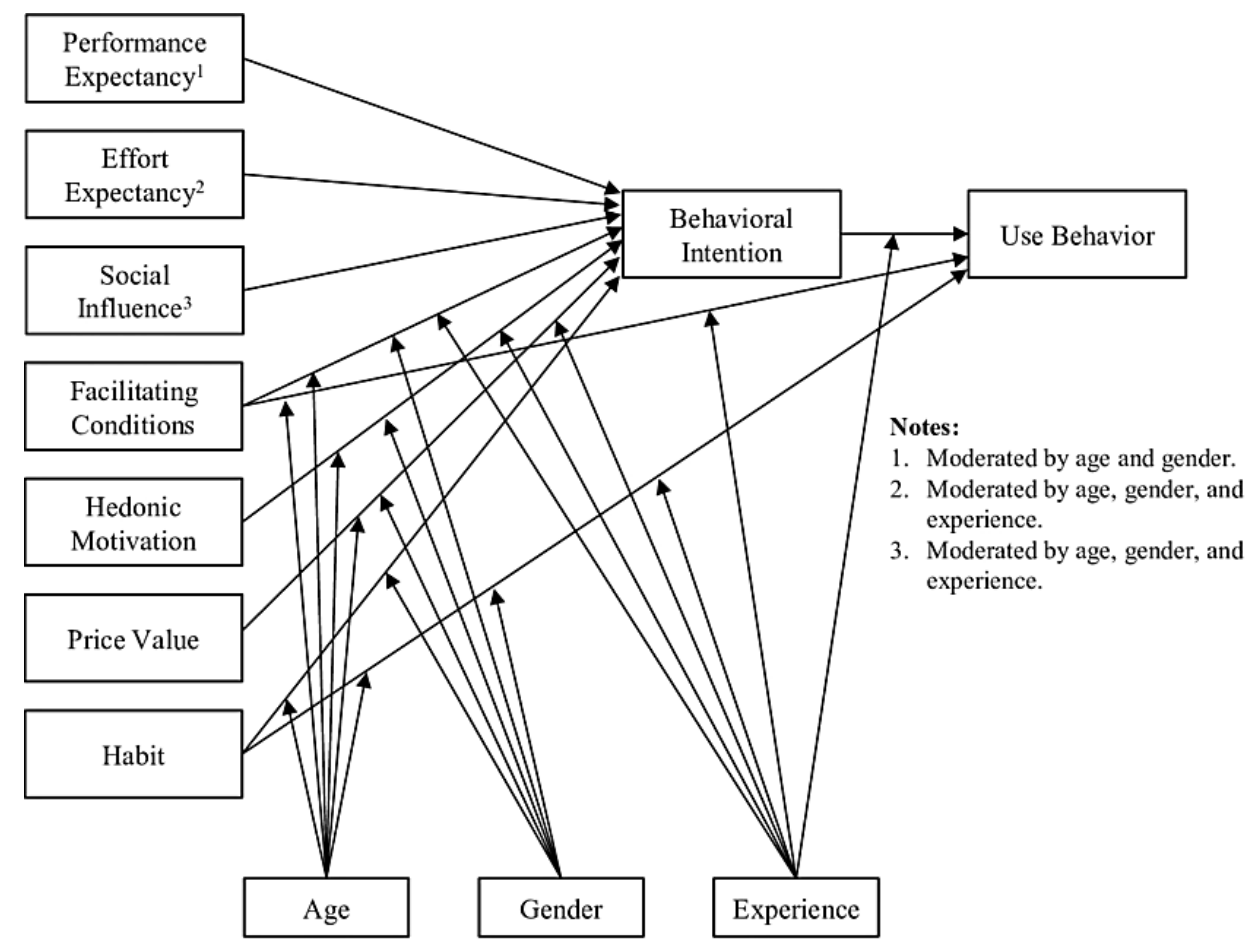

Figure 1. UTAUT-2 model Venkatesh et al. (2012) [4]

\section{2-4- The Implications of Innovative Personal}

According to De Vries and Shields (2006), flexibility, motivation, perseverance, and optimism are among the qualities of business leaders; apparently, these behavioral patterns develop from life experience rather than traits [34]. SME leaders that exhibit these traits boost not only their own personal resilience, but also their business's resilience. This strengthens the relationship between the leaders' individual resilience and the resilience of their business to adopt the new frontier of knowledge [35]. Self-efficacy in terms of cognitive adaptation and flexibility has been identified as a quality of a resilient corporate leader by previous researchers [36]. In perilous circumstances, such individuals will seek knowledge, inspiration, and solutions (e.g., acquiring information about new technologies, science, economics, trends, government policies, and so on) [37]. Their enthusiasm is not only for learning more, but also for putting what they have learned into process designs, coming up with new ideas, and mobilizing resources to accomplish desired outcomes. Such efforts have been termed 'creative and innovative leadership' by previous researchers [38]. As a result, corporate leaders should use business training to encourage workers' creativity and inventive production. Furthermore, corporate executives with a high risk aversion find it difficult to adopt new marketing technologies [39]. Business executives that have a low risk aversion, on the other hand, are more likely to take chances and act creatively. They've been hailed as fearless leaders. When using technology, risk aversion plays a role in deciding whether to employ digital marketing and which marketing method to apply [38]. 


\section{3- Research Methodology}

\section{3-1-Research Design}

This study conducted a comprehensive literature analysis and synthesis to investigate the factors that influence the intention of SMEs to embrace mobile applications, namely 'TNA', which is a smart phone mobile application developed as part of the Thailand government-funded project. The objective was to identify and categorize all key constructs using UTAUT-2 theory, as well as to establish a theoretical framework for future study on related constructs. Consistent with other systematic reviews, the limitation of the literature review to high-quality sources included in the Scopus database and covering the years $2020-2022$.

\section{3-2-Data Collection}

All sources needed to explicitly fall within the scope of tourism, business transition, digital technology, and innovation, especially under the circumstances of COVID-19 over the past years to ensure that all articles included met a threshold of quality as determined by journal centrality and academic standing. The lists of the top academic databases and search engines publishers such as Science Direct, Emerald Insight, SAGE journal, IEEE Xplore, SpringerLink, Palgrave, and Inderscience were searched, where the Science Direct host is placed as the main search engine to refine the specific words, contents, and journal publishers.

The keywords 'mobile applications', 'SMEs', 'digital technology (e.g. AI, AR, VR)', and 'smartphone' were combined with 'smart tourism', 'tourism', 'travel', 'SMEs', 'restaurants', 'hotels', 'destinations', and 'tourist attractions' to search for the abstract, title, and keywords of the journal articles. A total of 436 articles were found based on related topic content (See the characteristics based on articles sections in Table 1), including the percentage of four types of articles: review articles, research articles, conferences, and book chapters. Meanwhile, using a key specific word and publication contents to refine related research objectives based on UTAUT and UTAT-2 theory and the example of a process analysis (i.e., key criteria for selection) are shown in Figure 2. In total, 84 journal articles with (during 2020 to 2022) in the tourism and hospitality, information systems (IS), and business management fields were selected. Selected journal articles were directly exported to RIS format for Endnote software, which helped the authors organize the research. At the end of the data collection process, the authors independently reviewed all 48 selected journal articles to increase the reliability and validity.

Table 1. Number of publications related to mobile applications during the COVID-19 pandemic (2020 to 2022)

\begin{tabular}{|c|c|c|c|}
\hline \multicolumn{4}{|c|}{ Process of selected articles } \\
\hline 1. Mobile applications for SMEs tourism $(\mathrm{N}=436)$ & No. & 3. Mobile applications adoption articles $(\mathrm{N}=84)$ & No. \\
\hline Sample list of highest journals published articles & & Sample list of highest journals published articles & \\
\hline Tourism Management & 21 & Tourism Management & 17 \\
\hline Procedia Computer Science (20) & 20 & Tourism Management Perspectives & 10 \\
\hline Technological Forecasting and Social Change & 18 & Annals of Tourism Research & 8 \\
\hline Procedia - Social and Behavioural Sciences & 15 & Journal of Hospitality and Tourism Management & 7 \\
\hline Procedia Economics and Finance & 14 & International Journal of Hospitality Management & 5 \\
\hline Journal of Business Research & 13 & Technological Forecasting and Social Change & 5 \\
\hline International Journal of Information Management & 10 & Journal of Business Research & 5 \\
\hline International Journal of Hospitality Management & 6 & Journal of Destination Marketing \& Management & 4 \\
\hline International Hospitality Review & 5 & Telematics and Informatics & 3 \\
\hline \multicolumn{2}{|l|}{ 2. Of 169 selected from 436 articles (2020 to 2022$)$} & Expert Systems with Applications & 2 \\
\hline Sample list of highest journals published articles & & MIS Quarterly & 2 \\
\hline Tourism Management & 32 & Information \& Management & 1 \\
\hline Tourism Management Perspectives & 25 & Industrial Marketing Management & 1 \\
\hline Annals of Tourism Research & 15 & Journal of Management Information Systems & 1 \\
\hline Journal of Hospitality and Tourism Management & 15 & International Journal of Information Management & 1 \\
\hline International Journal of Hospitality Management & 14 & International Hospitality Review & 1 \\
\hline Technological Forecasting and Social Change & 13 & Technology in Society & 1 \\
\hline Journal of Business Research & 10 & Entrepreneurship and sustainability & 1 \\
\hline Journal of Destination Marketing \& Management & 10 & Others journals each for 1 article & 9 \\
\hline Others journals (plus 45 articles) & $\mathbf{N}=169$ & Total & 84 \\
\hline
\end{tabular}




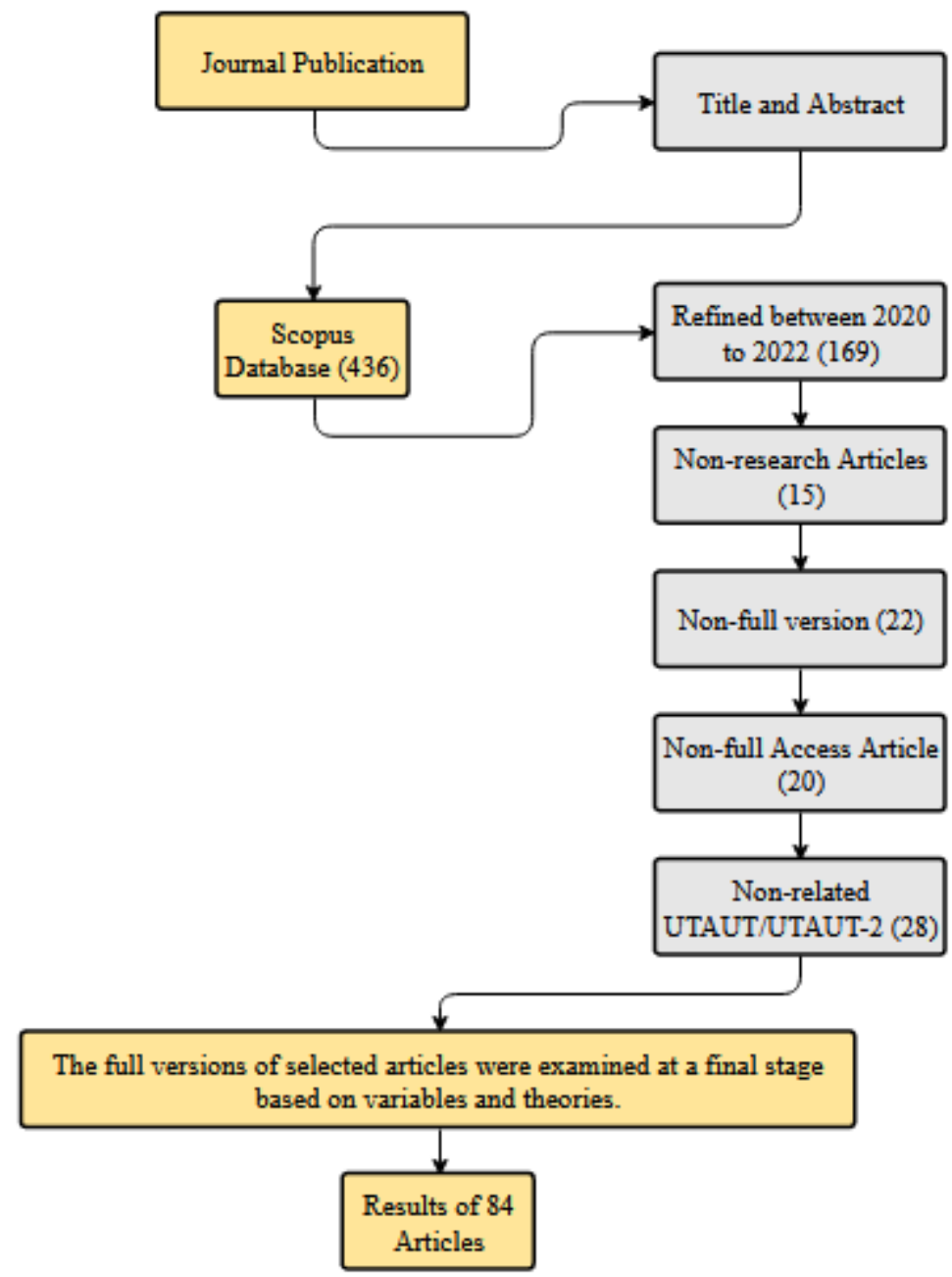

Figure 2. An example of a process analysis

\section{3-3-Research Analysis}

Using the principles of the grounded theory approach [40], a thematic analysis [41] was used to analyze the qualitative topics, content, and findings of the selected literature. Three qualitative data analysis strategies were used.

Firstly, the researcher employed the categorization approach of coding to extract new data or codes from the text and organize them into categories to create themes. It should ideally begin with the formation of data segment categories that enable data analysis and allow for comparisons within and across groups. Categorization in this study was accomplished by creating a table containing information about the author(s) of each paper, the year of publication, and other pertinent details. Table 2 shows how the literature publications were categorized based on the study's key objectives and research gap. Second, an integrative framework was constructed after analyzing publications related to the relevance of constructs and variables. This strategy was applied to identify whether those categories were determinants, dimensions, or outcomes of business performance by considering the context in which they were studied. This step allows developing a model of the causal connections among the categories, leading to a main theme that is presented in the proposed conceptual model framework and future research direction section.

The last technique is finding themes, which entails paraphrasing or summarizing each category, changing a node's category, and incorporating information into unconscious as well as conscious processing [41]. Ideally, the categories from the second stage would be gathered and combined to form subthemes of comparable phenomena that would eventually lead to a primary theme. In other words, the researcher had not simply programmed every linked skill into a single theme at this point, but had instead established sub-themes (coding the various dimensions relating to each theme). Figure 3 demonstrated publication trends and content related to SME strategy and technological changes, and Figure 4 shows a comparison of trending publications related to the intention of application adoption by SMEs. 


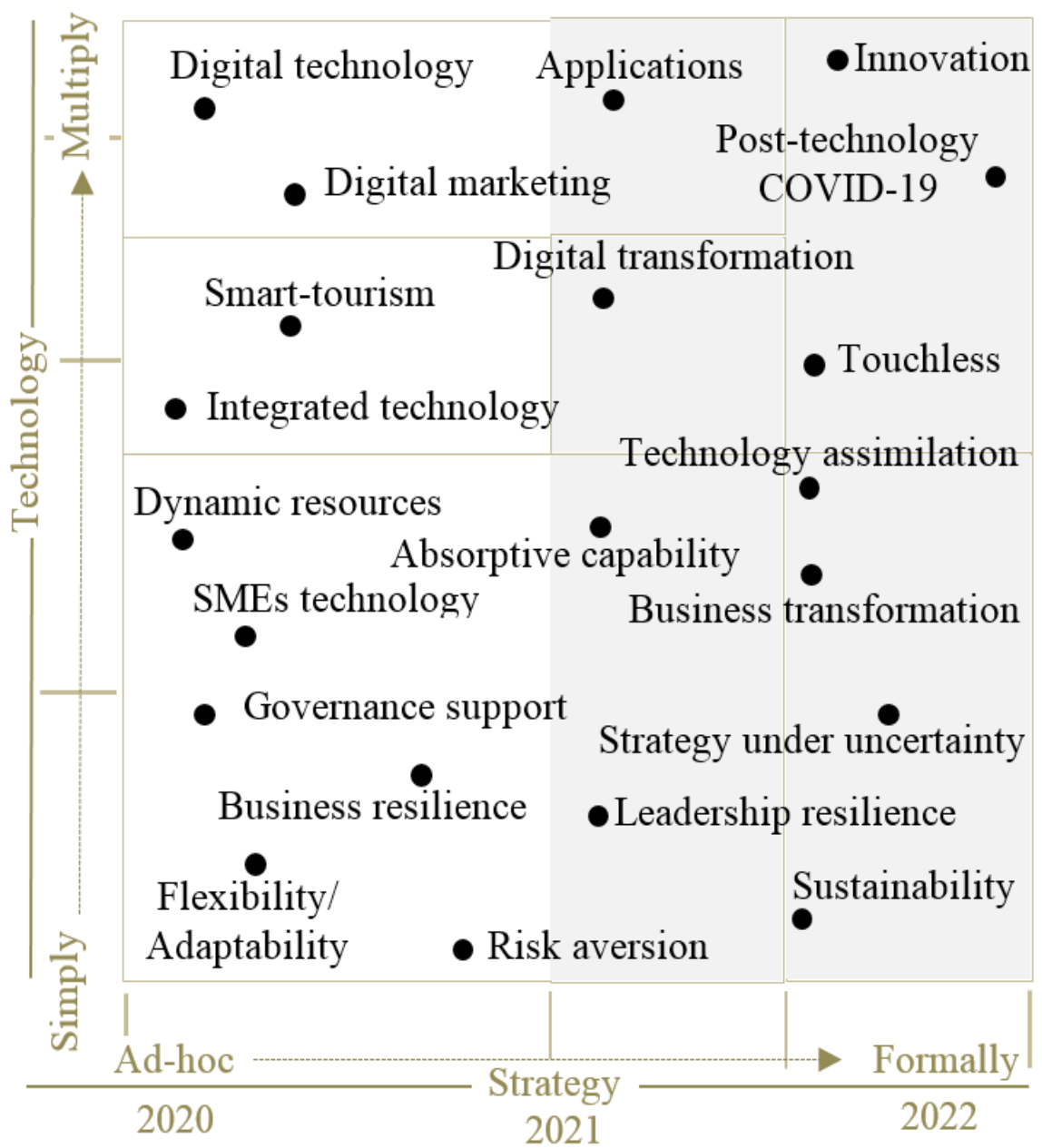

Figure 3. Publication trends and contents

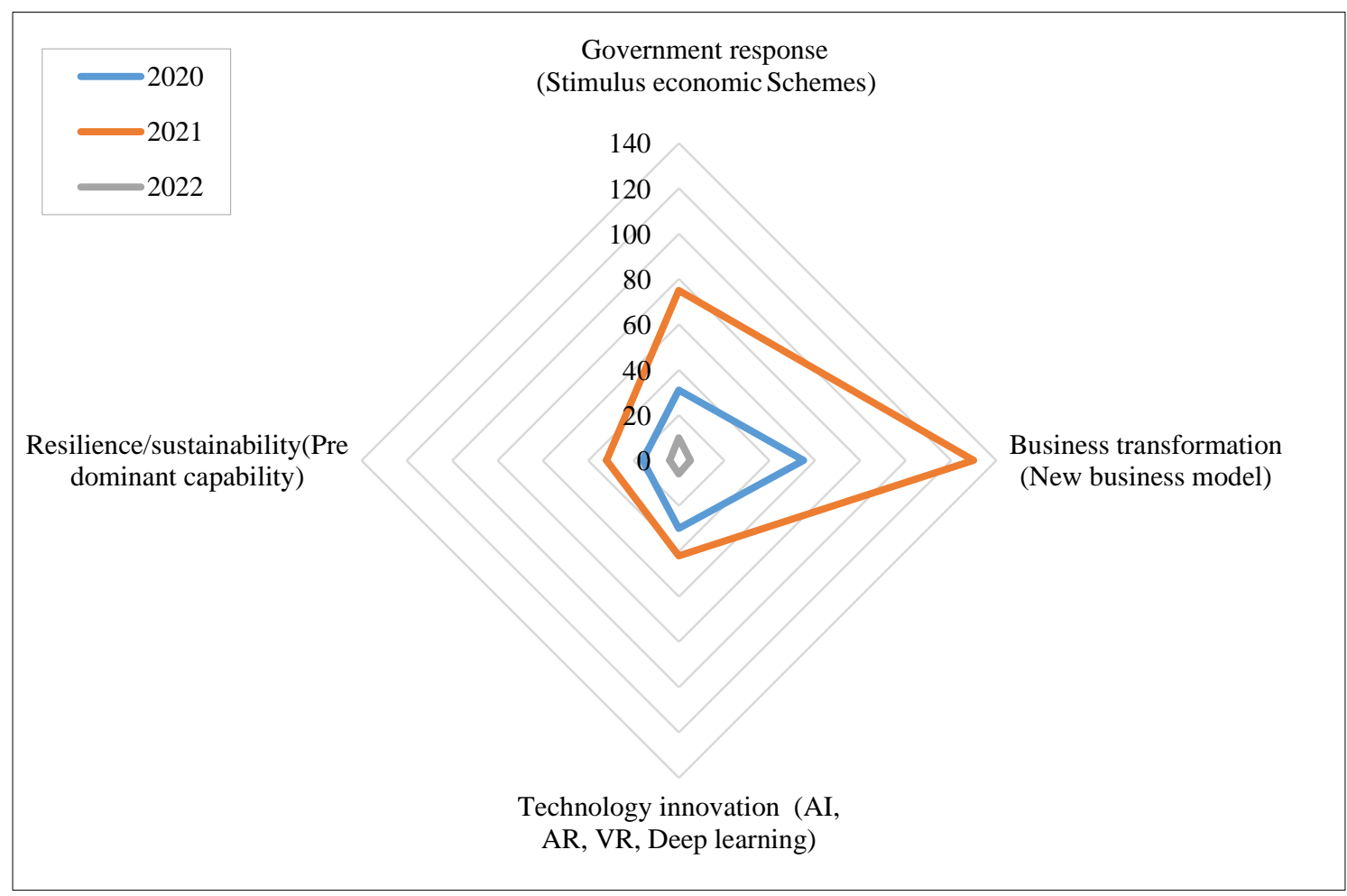

Figure 4. Comparison trending publications related to intention of application adoption by SMEs 
Table 2. Classification framework of categories, sub-themes and main themes of research constructs during the COVID-19 pandemic (2020 to 2022)

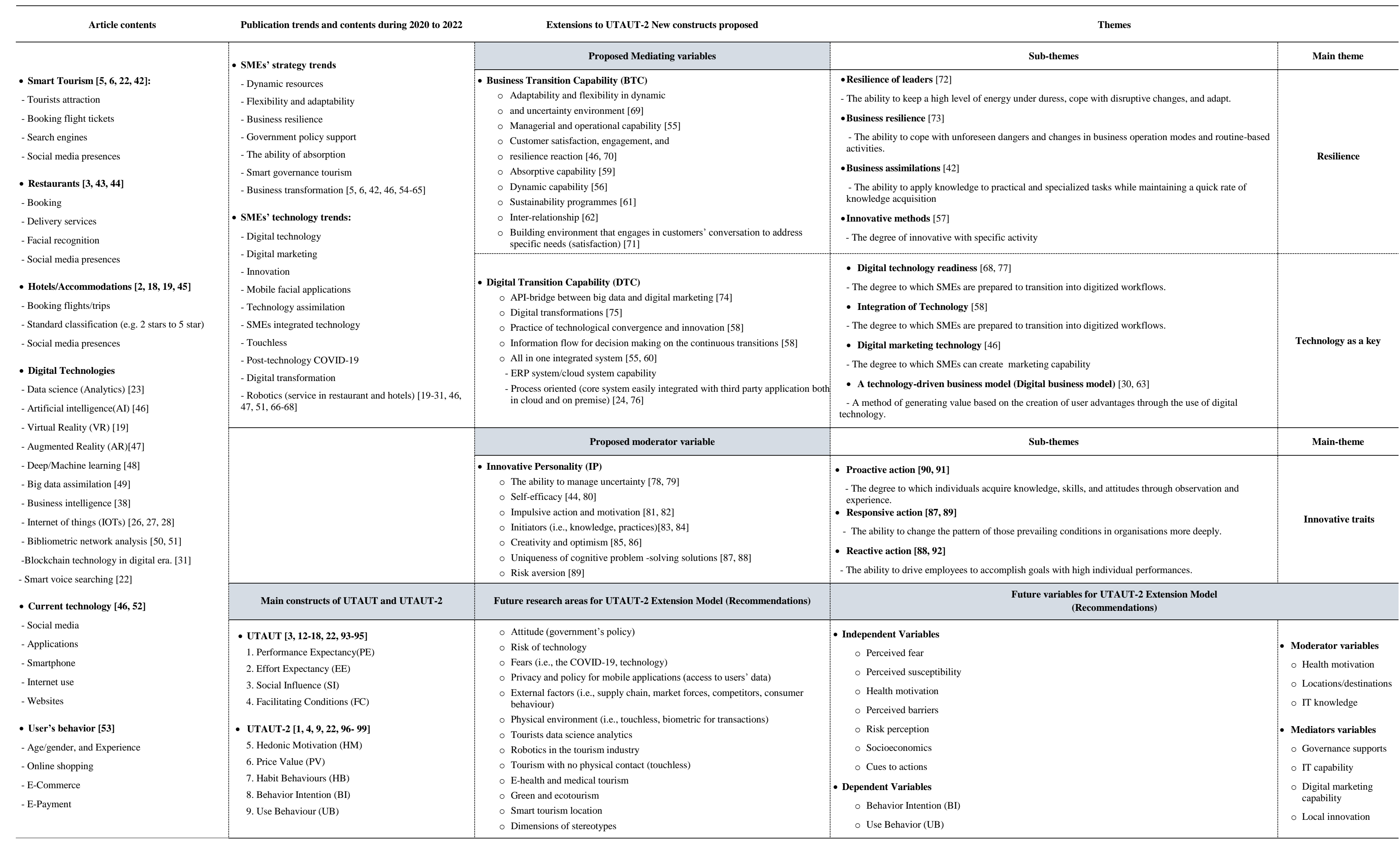




\section{4- Results and Proposed Research Framework Model}

\section{4-1-Results and Themes}

The findings produced from the thematic coding method, combining grounded theory techniques based on 84 selected articles, revealed three primary themes and their related sub-themes. Table 2 summarizes each of the three themes together with the future research dimensions. The 'Resilience' topic emphasized the ability to recover and retain adaptive behavior, which might help SMEs establish innovative process businesses and achieve long-term growth in their international trade operations. Leader resilience, business resilience, business assimilation, and innovative methods are some of the sub-themes. This implies that both leadership and business resilience may be important factors in developing a new innovative mechanism that allows SMEs to anticipate and respond to turbulent times. These include daily routine work by employees, the process of learning activities to collaborate and exchange knowledge, and exploration and exploitation-related networking capabilities. By doing this, the resilience of SMEs is also linked to the assimilation and absorption strategies and practices they utilize to adapt and evolve. It is supposed that the greater the SME's resilience, the greater its adaption, acquisition, absorption, and assimilation of new technologies, resources, and innovative capabilities.

Second, the theme 'Technology as a Key' refers to SMEs' capacity to generate and use opportunities at the cutting edge of digitalization. Such a shift necessitates the preparedness of SMEs' technology, processes, strategic planning, and methods for technology presence transfer. The digital transition is a game changer for SMEs where technology development can facilitate new business improvement models while innovative technology opens a range of new opportunities for enabling the creation of new business transformations. In doing this, creating a team (innovative units within the organization) engagement with formal and informal training programs, such as on-the-job training, coaching, and monitoring aspects to foster employees' being immediately more effective is required. A potential workflow process alternative could not only lead to improved efficiency and service levels, but also generate new capabilities. Such new capabilities lead to all-in-one integrated systems, data-driven workflows and processes for analytics and predictions, and new innovation opportunities around digital technologies.

The last theme, 'Innovative traits', focused on the ability of users to demonstrate their qualities and potential as individuals and as business leaders. Innovative traits are comprised of three subthemes: proactive, responsive, and reactive action. Proactive action is related to the degree to which individuals acquire knowledge, skills, and attitudes through observation and experience. Responsive action refers to the ability to change the patterns of those prevailing conditions in organizations more deeply, and reactive action refers to the ability to drive employees to accomplish goals with high individual performance. Unlike developing ambidextrous organizational learning (i.e., referring to simultaneously performing exploratory learning and exploitative learning), innovative traits emphasize more innovative personality actions, including self-efficacy (helping employees view themselves as idols), low risk aversion (taking high risks), being innovative and creative (creating more options), and motivation as some of the primary characteristics of such an innovative person (encouraging and inspiring). High performance of this attribute leads to advanced visionaries and the creation of their own cognitive knowledge. As a result, such leaders are making those crisis-related adjustments (not just for the COVID-19 pandemic) with the ability to construct their own cognitive knowledge.

The future research area includes relevance determinants regarding the external factors, subjective norms, consumer behavior, attitudes, trends, technological aspects, and all stakeholders related to the engagement of mobile applications by SMEs in the tourism sector. The perception of risks (e.g., diseases, natural hazards, fear, privacy issues, and so forth), physical touchless, and data science analytics, are considered a future trend for tourism industrial applications.

\section{4-2-Structural Model and Hypothesis Proposed}

The two key constructs of the UTAUT and its variant, the UTAUT2, are PE and EE. PE comprises 'Perceived benefits', and EE is considered similar to 'Perceived ease of use' based on TAM. Previous studies have shown that performance expectations, when combined with perceived ease of use of the information system and functionality, are more likely to generate behavioral intention and that effort expectancy has a major impact on behavioral intention [5, $45,68,77]$. In the context of mobile applications, prior research has examined SI, FC, HM, PV, and HB in a variety of contexts, and their relationship with BI has been reported as both significant and insignificant. This study proposed that BTC and DTC variables be expanded to serve as moderators and mediators for TNA adoption (see Figure 5). This is because SMEs have already engaged in SM and digital platforms. SMEs need varied approaches to operate businesses augmented by sophisticated technology usage. Experience will enhance cognitive knowledge, but ground-breaking activities (job-specific tasks) derived from creative techniques, such as the development of assimilation ability and IS integration, can help SMEs to design and establish their own innovative ways. This study argues that both BTC and DTC emerge as predominant influencer mediators toward the intention of TNA uptake. In the same vein, IP refers to the proactive, responsive, and reactive actions of an individual. IP could help bridge the gap towards a more sustainable future, regardless of age, gender, and experience. In other words, when a small business owner was once a customer and has now become an entrepreneur. Experience will recall it in a different way, but IP drives innovation in a proactive way, which embeds cognitive knowledge in further development of innovative ideas and the intention of TNA adoption. 


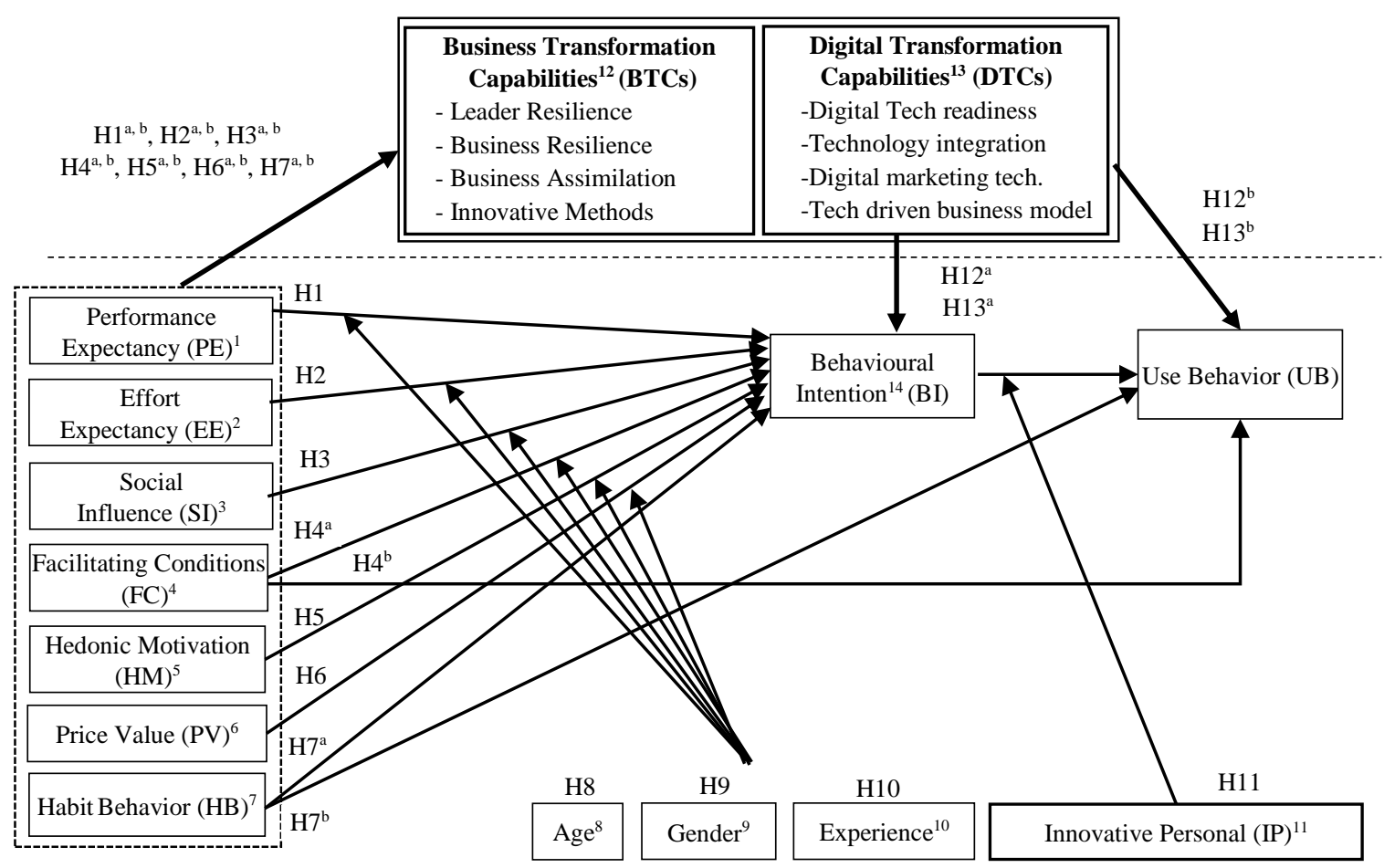

Figure 5. Proposed theoretical framework of TNA adoption

The extended model, comprising new mediators and moderators, UTAUT-2 main effects, should serve as a baseline for future researchers in refining the existing context and/or exploring new contexts with the desired parsimony. According to Figure 5, the original UTAUT-2 has been enhanced and extended in this study by developing the moderator and mediation constructs. Hypotheses proposed in the theoretical TNA intention adoption framework are outlined below:

H1: Performance Expectancy is positively related to behavioural intention.

H2: Effort Expectancy is positively related to behavioural intention.

H3: Social Influence is positively related to behavioural intention.

$\mathrm{H} 4^{\mathrm{a}}$ : Facilitating Conditions are positively related to behavioural intention.

$\mathrm{H} 4^{\text {b }}$ : Facilitating Conditions are positively related to use behavior.

H5: Hedonic Motivation is positively related to behavioural intention

H6: Price Value is positively related to behavioural intention.

$\mathrm{H} 7^{\mathrm{a}}$ : Habit Behavior is positively related to behavioural intention.

$\mathrm{H} 7^{\mathrm{b}}$ : Habit Behavior is positively related to use behavior.

H8: Demographic variable 'Age' moderates the effect of (PE, EE, SI, FC, HM, PV, and HB) on behavioural intention.

H9: Demographic variable 'Gender' moderates the effect of (PE, EE, SI, FC, HM, PV, and HB) on behavioural intention.

H10: Demographic variable 'Experience' moderates the effect of (PE, EE, SI, FC, HM, PV, and HB) on behavioural intention.

H11: Innovative Personal moderates the effect of behavioural intention on use behavior.

H12 ${ }^{\text {a }}$ Business Transformation Capabilities are positively associated with behavioural intention.

$\mathrm{H} 12^{\mathrm{b}}$ : Digital Transformation Capabilities are positively associated with use behavior.

H13 ${ }^{\text {a }}$ Business Transformation Capabilities are positively associated with behavioural intention.

H13 : Digital Transformation Capabilities are positively associated with use behavior.

H14: Behavioural Intention is positively related to use behavior. 


\section{Business and Digital Transformation Capabilities as Mediating Factors}
$\mathrm{H} 1: \mathrm{a}, \mathrm{b}$ the factor of BTC and DTC mediate the relationship among PE, BI and UB.
$\mathrm{H} 2$ : $\mathrm{a}, \mathrm{b}$ the factor of BTC and DTC mediate the relationship among EE, BI and UB.
H3: $a, b$ the factor of BTC and DTC mediate the relationship among SI, BI and UB.
H4: $a, b$ the factor of BTC and DTC mediate the relationship among FC, BI and UB.
H5: $a, b$ the factor of BTC and DTC mediate the relationship among HM, BI and UB.
H6: $a, b$ the factor of BTC and DTC mediate the relationship among PV, BI and UB.
H7: $a, b$ the factor of BTC and DTC mediate the relationship among HB, BI and UB

\section{5- Discussion}

Successful adoption of TNA based on mobile application platforms could be enhanced by the understanding of SMEs that it is not only about tools, but also about the perception of digitalization issues that affect their usage behavior. This study, thus, points to UTAUT-2 as the starting point for understanding the acceptance of technology adoption in SME businesses, which has significant effects on the adoption of TNA initiatives. Previous empirical research in mobile applications found that the original constructs, such as performance expectancy, effort expectancy, social influence and facilitating conditions, hedonic motivation, price value, and habit behavior, have direct and indirect effects on behavior intention and use behavior depending on demographic contexts and external factors [1, 4, 22, 96-99]. Because of its compound nature and its previously successful employment in similar contexts, UTAUT-2 seemed appropriate. It is designed to provide a holistic prediction of user behavior and their willingness to adopt new information systems and technological solutions. Compared to the previous models (UTAUT), [3, 12-18, 22, 93-95], the prosed theoretical framework has more effective explanation strength. From a technological standpoint, the TNA mobile application initiatives bridge digital technology with traditional smartphone technology. Thus, the complete picture is not only established when different components weaved around mobile application technologies are integrated with and leveraged by the SME systems, but also enables the investigation of the process of TNA adoption associated with the Thais' local business context.

The key findings of this study are to systematically analyze and synthesize previous research studies to generate three main themes (resilience, technology as a key, and innovative traits), leading to the extended UTUAT-2 variables with inclusively original constructs. Moreover, the results of this study revealed that the effects of both BTCs (i.e., leader and business resilience, business assimilation, and innovative methods) and DTCs (i.e., digital technology readiness, technology integration, digital marketing technology, and technology-driven business model) presumably depend on the readiness of SMEs' technology and their infrastructure. In line with previous research indicating that in dynamic and unpredictable incidents, adaptability and flexibility for business are essential [59, 56, 69]. Meanwhile, the findings of the present study found DTCs as a key aspect for business transformation, which is in line with previous studies indicating that information and data flow with potential analytical systems can enable SMEs for decision-making on continuous transitions [58]. In particular, the application programming interface serves as a link between big data and digital marketing, which leads to the new mechanism activities integrated with third-party applications and systems [24, 74]. Furthermore, the innovative individual or leader with self-efficacy, competency, motivation, creativity, low risk aversion, and a unique cognitive problem-solving solution is the key factor driving business continuity. In line with prior studies by several academics [38, 72, 84], this reaffirms that leaders affect business creation, intelligence, and business models for contingencies. To succeed in the entrepreneurial process, SMEs require a robust mobile-app-based business, and increased mobile application adoption boosts SMEs' long-term productivity substantially [100].

\section{6- Conclusion}

This study attempts to synthesize existing knowledge on the variables influencing the intention of a mobile application called 'TNA' for Thailand's hospitality and tourist industry sector. The emphasis is on SMEs, with a particular focus on restaurants, hotels, and tourist attractions. Using UTAUT-2 as the theoretical framework basis of this study paradigm, the present study found three main mediators and moderator variables, including Business Transformation Capabilities (BTC), Digital Transformation Capabilities (DTC), and Personal Innovativeness (PI). Each theme was developed from the synthesizing argument to complete this theoretical framework by using 84 selected research articles conducted with thematic analysis, incorporating a grounded theory approach to systematically generate themes. The proposed theoretical framework model of the UTAUT-2 extension is formulated, as are its hypotheses and future research directions. The novel contribution of this study emphasizes both the theoretical and practical understanding of the usage intention of mobile applications during the COVID-19 pandemic. On the theoretical level, this study constitutes the constructs based on UTAUT-2 theory as a research-based setting to fill a gap in research that explores the factors, particularly mediator and moderator variables, that could influence the adoption of mobile 
applications. On the practical level, this study provides insights and information about new capabilities that SME owners, managers, and practitioners should consider in order to differentiate their own capabilities (i.e., BTCs, DTCs, and IP). Hence, accelerating progress in business transition, particularly in the tourism sector, is creating opportunities for businesses across size and scale in emerging market countries to shift their capabilities during recession times.

\section{6-1-Limitations and Future Research}

Future research should address some limitations associated with the present study. Firstly, for example, only including three variables when expanding the UTAUT-2 model (or in this case, to help researchers segment the database) could have caused bias because the effect of other possible constructs, such as perceived risk, resistance to use, or the conditions of privacy, were not considered. Second, the present study focused on articles published between 2020 and 2021 with the aim of gathering and utilising recent COVID-19 pandemic academic literature. This might lead to a lack of knowledge about aspects of the broad viewpoint, such as perceived danger, fear, vulnerability, and socioeconomics, during lockdown. It appears important to investigate new internal, external, and moderator variables (i.e., as shown in Table 2) in addition to those in the original UTAUT-2, not only to expand the model but also to aid segmentation, with the goal of analyzing hitherto unconsidered new effects. This would bring fresh insights about user behaviour and TNA application usage patterns. In fact, future studies should focus on examining the suggested theoretical framework. The TNA's suitability for adoption and intended use by tourists and visitors is also encouraged.

\section{7- Declarations}

\section{7-1-Author Contributions}

Conceptualization, K.Y., D.A. and M.C.; methodology, K.Y.; validation, M.C., and D.A.; formal analysis, K.Y.; investigation, D.A.; resources, D.A. and M.C.; writing — original draft preparation, K.Y. and D.A.; writing-review and editing, M.C.; supervision, P.M.; project administration, P.M.; funding acquisition, P.M. All authors have read and agreed to the published version of the manuscript.

\section{7-2-Data Availability Statement}

The data presented in this study are available in article.

\section{7-3-Funding}

This research project funding was supported by Thailand Science Research and Innovation (TSRI) (Fundamental Fund/annual funding 2021) with Grants Number: 2199055.

\section{7-4-Conflicts of Interest}

The authors declare that there is no conflict of interests regarding the publication of this manuscript. In addition, the ethical issues, including plagiarism, informed consent, misconduct, data fabrication and/or falsification, double publication and/or submission, and redundancies have been completely observed by the authors.

\section{8- References}

[1] MacSween, S., \& Canziani, B. (2021). Travel booking intentions and information searching during COVID-19. International Hospitality Review, 35(2), 208-224. doi:10.1108/ihr-08-2020-0046.

[2] Yang, H., Song, H., Cheung, C., \& Guan, J. (2021). How to enhance hotel guests' acceptance and experience of smart hotel technology: An examination of visiting intentions. International Journal of Hospitality Management, 97(97), 103000. doi:10.1016/j.ijhm.2021.103000.

[3] Ciftci, O., Choi, E. K. (Cindy), \& Berezina, K. (2021). Let's face it: Are customers ready for facial recognition technology at quick-service restaurants? International Journal of Hospitality Management, 95(95), 102941. doi:10.1016/j.ijhm.2021.102941.

[4] Venkatesh, V., Thong, J. Y. L., \& Xu, X. (2012). Consumer acceptance and use of information technology: Extending the unified theory of acceptance and use of technology. MIS Quarterly: Management Information Systems, 36(1), 157-178. doi:10.2307/41410412.

[5] Park, S., Xu, Y., Jiang, L., Chen, Z., \& Huang, S. (2020). Spatial structures of tourism destinations: A trajectory data mining approach leveraging mobile big data. Annals of Tourism Research, 84(84), 102973. doi:10.1016/j.annals.2020.102973.

[6] Scuttari, A. (2021). Tourism experiences in motion. Mobile, visual and psychophysiological methods to capture tourists "on the move.” Tourism Management Perspectives, 38(38), 100825. doi:10.1016/j.tmp.2021.100825.

[7] Kemp, S. (2021). Digital 2021 Global Digital Overview, Datareportal. Available online: https://datareportal.com/reports/digital2021-thailand (accessed on December 2020). 
[8] Canhoto, A. I., Quinton, S., Pera, R., Molinillo, S., \& Simkin, L. (2021). Digital strategy aligning in SMEs: A dynamic capabilities perspective. Journal of Strategic Information Systems, 30(3), 101682. doi:10.1016/j.jsis.2021.101682.

[9] Venkatesh, V., Morris, M. G., Davis, G. B., \& Davis, F. D. (2003). User acceptance of information technology: Toward a unified view. MIS Quarterly: Management Information Systems, 27(3), 425-478. doi:10.2307/30036540.

[10] Davis, F. D. (1989). Perceived usefulness, perceived ease of use, and user acceptance of information technology. MIS Quarterly: Management Information Systems, 13(3), 319-339. doi:10.2307/249008.

[11] Ajzen, I. (1985). From Intentions to Actions: A Theory of Planned Behavior. In J. Kuhl \& J. Beckmann (Eds.), Action Control (pp. 11-39). Springer. doi:10.1007/978-3-642-69746-3_2.

[12] Kalinić, Z., Marinković, V., Kalinić, L., \& Liébana-Cabanillas, F. (2021). Neural network modeling of consumer satisfaction in mobile commerce: An empirical analysis. Expert Systems with Applications, 175(175), 114803. doi:10.1016/j.eswa.2021.114803.

[13] Khanra, S., Dhir, A., Kaur, P., \& Joseph, R. P. (2021). Factors influencing the adoption postponement of mobile payment services in the hospitality sector during a pandemic. Journal of Hospitality and Tourism Management, 46(46), 26-39. doi:10.1016/j.jhtm.2020.11.004.

[14] Jadil, Y., Rana, N. P., \& Dwivedi, Y. K. (2021). A meta-analysis of the UTAUT model in the mobile banking literature: The moderating role of sample size and culture. Journal of Business Research, 132(132), $354-372$. doi:10.1016/j.jbusres.2021.04.052.

[15] Arfi, W. Ben, Nasr, I. Ben, Kondrateva, G., \& Hikkerova, L. (2021). The role of trust in intention to use the IoT in eHealth: Application of the modified UTAUT in a consumer context. Technological Forecasting and Social Change, 167(167), 120688. doi:10.1016/j.techfore.2021.120688.

[16] Al Aufa, B., Renindra, I. S., Putri, J. S., \& Nurmansyah, M. I. (2020). An application of the Unified Theory of Acceptance and Use of Technology (UTAUT) model for understanding patient perceptions on using hospital mobile application. Enfermeria Clinica, 30(30), 110-113. doi:10.1016/j.enfcli.2020.06.025.

[17] Zhao, Y., \& Bacao, F. (2020). What factors determining customer continuingly using food delivery apps during 2019 novel coronavirus pandemic period? International Journal of Hospitality Management, 91(91), 102683. doi:10.1016/j.ijhm.2020.102683.

[18] Sun, S., Lee, P. C., Law, R., \& Zhong, L. (2020). The impact of cultural values on the acceptance of hotel technology adoption from the perspective of hotel employees. Journal of Hospitality and Tourism Management, 44(44), 61-69. doi:10.1016/j.jhtm.2020.04.012.

[19] Loureiro, S. M. C., Guerreiro, J., \& Ali, F. (2020). 20 years of research on virtual reality and augmented reality in tourism context: A text-mining approach. Tourism Management, 77(77), 104028. doi:10.1016/j.tourman.2019.104028.

[20] Xie, G., Qian, Y., \& Wang, S. (2021). Forecasting Chinese cruise tourism demand with big data: An optimized machine learning approach. Tourism Management, 82(82), 104208. doi:10.1016/j.tourman.2020.104208.

[21] Tussyadiah, I. P., Wang, D., Jung, T. H., \& tom Dieck, M. C. (2018). Virtual reality, presence, and attitude change: Empirical evidence from tourism. Tourism Management, 66(66), 140-154. doi:10.1016/j.tourman.2017.12.003.

[22] Cabrera-Sánchez, J. P., Villarejo-Ramos, Á. F., Liébana-Cabanillas, F., \& Shaikh, A. A. (2021). Identifying relevant segments of AI applications adopters - Expanding the UTAUT2's variables. Telematics and Informatics, 58(58), 101529. doi:10.1016/j.tele.2020.101529.

[23] Barnes, S. J., \& Kirshner, S. N. (2021). Understanding the impact of host facial characteristics on Airbnb pricing: Integrating facial image analytics into tourism research. Tourism Management, 83(83), 104235. doi:10.1016/j.tourman.2020.104235.

[24] Kontogianni, A., Alepis, E., \& Patsakis, C. (2022). Promoting smart tourism personalised services via a combination of deep learning techniques. Expert Systems with Applications, 187(187), 115964. doi:10.1016/j.eswa.2021.115964.

[25] Bi, J. W., Li, H., \& Fan, Z. P. (2021). Tourism demand forecasting with time series imaging: A deep learning model. Annals of Tourism Research, 90(90), 103255. doi:10.1016/j.annals.2021.103255.

[26] Pappas, N., Caputo, A., Pellegrini, M. M., Marzi, G., \& Michopoulou, E. (2021). The complexity of decision-making processes and IoT adoption in accommodation SMEs. Journal of Business Research, 131(131), 573-583. doi:10.1016/j.jbusres.2021.01.010.

[27] Leroux, E., \& Pupion, P. C. (2022). Smart territories and IoT adoption by local authorities: A question of trust, efficiency, and relationship with the citizen-user-taxpayer. Technological Forecasting and Social Change, 174(174), 121195. doi:10.1016/j.techfore.2021.121195. 
[28] Leite, E. (2022). Innovation networks for social impact: An empirical study on multi-actor collaboration in projects for smart cities. Journal of Business Research, 139(139), 325-337. doi:10.1016/j.jbusres.2021.09.072.

[29] Dwivedi, S. K., Amin, R., Vollala, S., \& Chaudhry, R. (2020). Blockchain-based secured event-information sharing protocol in internet of vehicles for smart cities. Computers and Electrical Engineering, 86(86), 106719. doi:10.1016/j.compeleceng.2020.106719.

[30] Aghaei, H., Naderibeni, N., \& Karimi, A. (2021). Designing a tourism business model on block chain platform. Tourism Management Perspectives, 39(39), 100845. doi:10.1016/j.tmp.2021.100845.

[31] Rashideh, W. (2020). Blockchain technology framework: Current and future perspectives for the tourism industry. Tourism Management, 80(80), 104125. doi:10.1016/j.tourman.2020.104125.

[32] Zhu, W., \& Shang, F. (2021). Rural smart tourism under the background of internet plus. Ecological Informatics, 65(65), 101424. doi:10.1016/j.ecoinf.2021.101424.

[33] Langley, D. J., van Doorn, J., Ng, I. C. L., Stieglitz, S., Lazovik, A., \& Boonstra, A. (2021). The Internet of Everything: Smart things and their impact on business models. Journal of Business Research, 122(122), 853-863. doi:10.1016/j.jbusres.2019.12.035.

[34] De Vries, H. E. R. B., \& Shields, M. I. C. H. E. L. L. E. (2006). Towards a theory of entrepreneurial resilience: A case study analysis of New Zealand SME owner operators. New Zealand Journal of Applied Business Research, 5(1), 33-43.

[35] Župerkienė, E., Šimanskienė, L., Labanauskaitė, D., Melnikova, J., \& Davidavičienė, V. (2021). The COVID-19 Pandemic and Resilience of SME's in Lithuania. Entrepreneurship and Sustainability Issues, 8(3), 53-65. doi:10.9770/jesi.2021.8.3(4).

[36] Bandura, A. (1997). The anatomy of stages of change. In American journal of health promotion : AJHP (Vol. 12, Issue 1, pp. 810). W.H. Freeman. doi:10.4278/0890-1171-12.1.8.

[37] Saad, M. H., Hagelaar, G., van der Velde, G., \& Omta, S. W. F. (2021). Conceptualization of SMEs' business resilience: A systematic literature review. Cogent Business and Management, 8(1), 1938347. doi:10.1080/23311975.2021.1938347.

[38] Southwick, F. S., Martini, B. L., Charney, D. S., \& Southwick, S. M. (2017). Leadership and Resilience. In J. Marques \& S. Dhiman (Eds.), Leadership Today: Practices for Personal and Professional Performance (pp. 315-333). Springer International Publishing. doi:10.1007/978-3-319-31036-7_18.

[39] Franken, J. R. V., Pennings, J. M. E., \& Garcia, P. (2014). Measuring the effect of risk attitude on marketing behavior. Agricultural Economics (United Kingdom), 45(5), 525-535. doi:10.1111/agec.12104.

[40] Corbin, J. M., \& Strauss, A. (1990). Grounded theory research: Procedures, canons, and evaluative criteria. Qualitative Sociology, 13(1), 3-21. doi:10.1007/BF00988593.

[41] Boyatzis, R. E. (1998). Transforming Qualitative Information: Thematic Analysis and Code Development. Prefix Transforming Qualitative Information: Thematic Analysis and Code Development. CA: Sage: Thousand Oaks.

[42] Stylos, N., Fotiadis, A. K., Shin, D. (Don), \& Huan, T. C. T. (2021). Beyond smart systems adoption: Enabling diffusion and assimilation of smartness in hospitality. International Journal of Hospitality Management, 98(98), 103042. doi:10.1016/j.ijhm.2021.103042.

[43] Dirsehan, T., \& Cankat, E. (2021). Role of mobile food-ordering applications in developing restaurants' brand satisfaction and loyalty in the pandemic period. Journal of Retailing and Consumer Services, 62(62), 102608. doi:10.1016/j.jretconser.2021.102608.

[44] Min, J., Kim, J., \& Yang, K. (2021). How generations differ in coping with a pandemic: The case of restaurant industry. Journal of Hospitality and Tourism Management, 48(48), 280-288. doi:10.1016/j.jhtm.2021.06.017.

[45] Han, S. H., Lee, J., Edvardsson, B., \& Verma, R. (2021). Mobile technology adoption among hotels: Managerial issues and opportunities. Tourism Management Perspectives, 38(38), 100811. doi:10.1016/j.tmp.2021.100811.

[46] Sharma, A., Sharma, S., \& Chaudhary, M. (2020). Are small travel agencies ready for digital marketing? Views of travel agency managers. Tourism Management, 79(79), 104078. doi:10.1016/j.tourman.2020.104078.

[47] Cranmer, E. E., tom Dieck, M. C., \& Fountoulaki, P. (2020). Exploring the value of augmented reality for tourism. Tourism Management Perspectives, 35(35), 100672. doi:10.1016/j.tmp.2020.100672.

[48] Ma, L., \& Sun, B. (2020). Machine learning and AI in marketing - Connecting computing power to human insights. International Journal of Research in Marketing, 37(3), 481-504. doi:10.1016/j.ijresmar.2020.04.005.

[49] Gunasekaran, A., Papadopoulos, T., Dubey, R., Wamba, S. F., Childe, S. J., Hazen, B., \& Akter, S. (2017). Big data and predictive analytics for supply chain and organizational performance. Journal of Business Research, 70(70), 308-317. doi:10.1016/j.jbusres.2016.08.004. 
[50] Krishen, A. S., Dwivedi, Y. K., Bindu, N., \& Kumar, K. S. (2021). A broad overview of interactive digital marketing: A bibliometric network analysis. Journal of Business Research, 131(131), 183-195. doi:10.1016/j.jbusres.2021.03.061.

[51] Di Vaio, A., Hassan, R., \& Alavoine, C. (2022). Data intelligence and analytics: A bibliometric analysis of human-Artificial intelligence in public sector decision-making effectiveness. Technological Forecasting and Social Change, 174(174), 121201. doi:10.1016/j.techfore.2021.121201.

[52] Eze, S. C., Chinedu-Eze, V. C. A., Okike, C. K., \& Bello, A. O. (2020). Critical factors influencing the adoption of digital marketing devices by service-oriented micro-businesses in Nigeria: A thematic analysis approach. Humanities and Social Sciences Communications, 7(1), 1-14. doi:10.1057/s41599-020-00580-1.

[53] Mulier, L., Slabbinck, H., \& Vermeir, I. (2021). This Way Up: The Effectiveness of Mobile Vertical Video Marketing. Journal of Interactive Marketing, 55(55), 1-15. doi:10.1016/j.intmar.2020.12.002.

[54] Rodríguez, I., Williams, A. M., \& Hall, C. M. (2014). Tourism innovation policy: Implementation and outcomes. Annals of Tourism Research, 49(49), 76-93. doi:10.1016/j.annals.2014.08.004.

[55] Moyle, C. lee, Moyle, B., \& Burgers, H. (2020). Entrepreneurial strategies and tourism industry growth. Tourism Management Perspectives, 35(35), 100708. doi:10.1016/j.tmp.2020.100708.

[56] Student, J., Kramer, M. R., \& Steinmann, P. (2020). Simulating emerging coastal tourism vulnerabilities: an agent-based modelling approach. Annals of Tourism Research, 85(85), 103034. doi:10.1016/j.annals.2020.103034.

[57] García-Villaverde, P. M., Ruiz-Ortega, M. J., Hurtado-Palomino, A., De La Gala-Velásquez, B., \& Zirena-Bejarano, P. P. (2021). Social capital and innovativeness in firms in cultural tourism destinations: Divergent contingent factors. Journal of Destination Marketing and Management, 19(19), 100529. doi:10.1016/j.jdmm.2020.100529.

[58] Hussain, Z. (2021). Paradigm of technological convergence and digital transformation: The challenges of $\mathrm{CH}$ sectors in the global COVID-19 pandemic and commencing resilience-based structure for the post-COVID-19 era. Digital Applications in Archaeology and Cultural Heritage, 21(21), 182. doi:10.1016/j.daach.2021.e00182.

[59] Puriwat, W., \& Tripopsakul, S. (2021). Exploring factors influencing open innovation adoption in smes: The evidence from emerging markets. Emerging Science Journal, 5(4), 533-544. doi:10.28991/esj-2021-01295.

[60] Sharma, G. D., Thomas, A., \& Paul, J. (2021). Reviving tourism industry post-COVID-19: A resilience-based framework. Tourism Management Perspectives, 37(37), 100786. doi:10.1016/j.tmp.2020.100786.

[61] Suno Wu, J., Barbrook-Johnson, P., \& Font, X. (2021). Participatory complexity in tourism policy: Understanding sustainability programmes with participatory systems mapping. Annals of Tourism Research, 90(90), 103269. doi:10.1016/j.annals.2021.103269.

[62] Elvekrok, I., Veflen, N., Scholderer, J., \& Sørensen, B. T. (2022). Effects of network relations on destination development and business results. Tourism Management, 88(88), 104402. doi:10.1016/j.tourman.2021.104402.

[63] Perelygina, M., Kucukusta, D., \& Law, R. (2022). Digital business model configurations in the travel industry. Tourism Management, 88(88), 104408. doi:10.1016/j.tourman.2021.104408.

[64] Tse, S., \& Tung, V. W. S. (2022). Understanding residents' attitudes towards tourists: Connecting stereotypes, emotions and behaviours. Tourism Management, 89(89), 104435. doi:10.1016/j.tourman.2021.104435.

[65] Mandić, A., \& Kennell, J. (2021). Smart governance for heritage tourism destinations: Contextual factors and destination management organization perspectives. Tourism Management Perspectives, 39(39), 100862. doi:10.1016/j.tmp.2021.100862.

[66] Fuentes-Moraleda, L., Díaz-Pérez, P., Orea-Giner, A., Muñoz- Mazón, A., \& Villacé-Molinero, T. (2020). Interaction between hotel service robots and humans: A hotel-specific Service Robot Acceptance Model (sRAM). Tourism Management Perspectives, 36(36), 100751. doi:10.1016/j.tmp.2020.100751.

[67] Tavitiyaman, P., Qu, H., Tsang, W. sze L., \& Lam, C. wah R. (2021). The influence of smart tourism applications on perceived destination image and behavioral intention: The moderating role of information search behavior. Journal of Hospitality and Tourism Management, 46(46), 476-487. doi:10.1016/j.jhtm.2021.02.003.

[68] Reif, J., \& Schmücker, D. (2020). Exploring new ways of visitor tracking using big data sources: Opportunities and limits of passive mobile data for tourism. Journal of Destination Marketing and Management, 18(18), 100481. doi:10.1016/j.jdmm.2020.100481.

[69] Burggräf, P., Dannapfel, M., Adlon, T., \& Kasalo, M. (2020). Adaptivity and adaptability as design parameters of cognitive worker assistance for enabling agile assembly systems. Procedia CIRP, 97(97), 224-229. doi:10.1016/j.procir.2020.05.229.

[70] Aheleroff, S., Mostashiri, N., Xu, X., \& Zhong, R. Y. (2021). Mass Personalisation as a Service in Industry 4.0: A Resilient Response Case Study. Advanced Engineering Informatics, 50(50), 101438. doi:10.1016/j.aei.2021.101438. 
[71] Yawised, K., Ellis, L., \& Wong, M. C. (2018). the Role and Nature of Scrm in Australian Private Sector: an Exploratory Study. Asia Pacific Journal of Contemporary Education and Communication Technology, 4(1), $139-150$. doi:10.25275/apjcectv4i1edu16.

[72] Ruiz-Palomino, P., Yáñez-Araque, B., Jiménez-Estévez, P., \& Gutiérrez-Broncano, S. (2022). Can servant leadership prevent hotel employee depression during the COVID-19 pandemic? A mediating and multigroup analysis. Technological Forecasting and Social Change, 174(174), 121192. doi:10.1016/j.techfore.2021.121192.

[73] Li, B., Zhong, Y. Y., Zhang, T., \& Hua, N. (2021). Transcending the COVID-19 crisis: Business resilience and innovation of the restaurant industry in China. Journal of Hospitality and Tourism Management, 49(49), 44-53. doi:10.1016/j.jhtm.2021.08.024.

[74] Wulf, J., \& Blohm, I. (2020). Fostering Value Creation with Digital Platforms: A Unified Theory of the Application Programming Interface Design. Journal of Management Information Systems, 37(1), $251-281$. doi:10.1080/07421222.2019.1705514.

[75] Wang, W. Y. C., \& Wang, Y. (2020). Analytics in the era of big data: The digital transformations and value creation in industrial marketing. Industrial Marketing Management, 86(86), 12-15. doi:10.1016/j.indmarman.2020.01.005.

[76] Schneckenberg, D., Benitez, J., Klos, C., Velamuri, V. K., \& Spieth, P. (2021). Value creation and appropriation of software vendors: A digital innovation model for cloud computing. Information and Management, 58(4), 103463. doi:10.1016/j.im.2021.103463.

[77] Palos-Sanchez, P., Saura, J. R., Velicia-Martin, F., \& Cepeda-Carrion, G. (2021). A business model adoption based on tourism innovation: Applying a gratification theory to mobile applications. European Research on Management and Business Economics, 27(2), 100149. doi:10.1016/j.iedeen.2021.100149.

[78] Arabadzhyan, A., Figini, P., \& Zirulia, L. (2021). Hotels, prices and risk premium in exceptional times: The case of Milan hotels during the first COVID-19 outbreak. Annals of Tourism Research Empirical Insights, 2(2), 100023. doi:10.1016/j.annale.2021.100023.

[79] Xie, K., Heo, C. Y., \& Mao, Z. E. (2021). Do professional hosts matter? Evidence from multi-listing and full-time hosts in Airbnb. Journal of Hospitality and Tourism Management, 47(47), 413-421. doi:10.1016/j.jhtm.2021.04.016.

[80] Leung, X. Y., \& Cai, R. (2021). How pandemic severity moderates digital food ordering risks during COVID-19: An application of prospect theory and risk perception framework. Journal of Hospitality and Tourism Management, 47(47), 497-505. doi:10.1016/j.jhtm.2021.05.002.

[81] Lee, Y., Lee, S., \& Kim, D. Y. (2021). Exploring hotel guests' perceptions of using robot assistants. Tourism Management Perspectives, 37(37), 100781. doi:10.1016/j.tmp.2020.100781.

[82] Do, H. N., Shih, W., \& Ha, Q. A. (2020). Effects of mobile augmented reality apps on impulse buying behavior: An investigation in the tourism field. Heliyon, 6(8), 4667. doi:10.1016/j.heliyon.2020.e04667.

[83] Hietschold, N., Reinhardt, R., \& Gurtner, S. (2020). Who put the "NO" in Innovation? Innovation resistance leaders' behaviors and self-identities. Technological Forecasting and Social Change, 158(158), 120177. doi:10.1016/j.techfore.2020.120177.

[84] Lombardi, S., Pina e Cunha, M., \& Giustiniano, L. (2021). Improvising resilience: The unfolding of resilient leadership in COVID-19 times. International Journal of Hospitality Management, 95(95), 102904. doi:10.1016/j.ijhm.2021.102904.

[85] Tapanainen, T., Dao, T. K., \& Nguyen, T. T. H. (2021). Impacts of online word-of-mouth and personalities on intention to choose a destination. Computers in Human Behavior, 116(116), 106656. doi:10.1016/j.chb.2020.106656.

[86] Kim, M. J., Lee, C. K., \& Preis, M. W. (2020). The impact of innovation and gratification on authentic experience, subjective well-being, and behavioral intention in tourism virtual reality: The moderating role of technology readiness. Telematics and Informatics, 49(49), 101349. doi:10.1016/j.tele.2020.101349.

[87] Liu, X., Wang, D., \& Gretzel, U. (2022). On-site decision-making in smartphone-mediated contexts. Tourism Management, 88(88), 104424. doi:10.1016/j.tourman.2021.104424.

[88] Kim, E. J., \& Pomirleanu, N. (2021). Effective redesign strategies for tourism management in a crisis context: A theory-in-use approach. Tourism Management, 87(87), 104359. doi:10.1016/j.tourman.2021.104359.

[89] Im, J., Kim, J., \& Choeh, J. Y. (2021). COVID-19, social distancing, and risk-averse actions of hospitality and tourism consumers: A case of South Korea. Journal of Destination Marketing and Management, 20(20), 100566. doi:10.1016/j.jdmm.2021.100566.

[90] Richards, G. (2020). Designing creative places: The role of creative tourism. Annals of Tourism Research, 85(85), 102922. doi:10.1016/j.annals.2020.102922. 
[91] Sarantou, M., Kugapi, O., \& Huhmarniemi, M. (2021). Context mapping for creative tourism. Annals of Tourism Research, 86(86), 103064. doi:10.1016/j.annals.2020.103064.

[92] Goh, H. C. (2021). Strategies for post-Covid-19 prospects of Sabah's tourist market - Reactions to shocks caused by pandemic or reflection for sustainable tourism? Research in Globalization, 3(3), 100056. doi:10.1016/j.resglo.2021.100056.

[93] Kim, M. J., \& Hall, C. M. (2020). What drives visitor economy crowdfunding? The effect of digital storytelling on unified theory of acceptance and use of technology. Tourism Management Perspectives, 34(34), 100638. doi:10.1016/j.tmp.2020.100638.

[94] Abou-Shouk, M., \& Soliman, M. (2021). The impact of gamification adoption intention on brand awareness and loyalty in tourism: The mediating effect of customer engagement. Journal of Destination Marketing and Management, 20(20), 100559. doi:10.1016/j.jdmm.2021.100559.

[95] Begany, G. M., \& Gil-Garcia, J. R. (2021). Understanding the actual use of open data: Levels of engagement and how they are related. Telematics and Informatics, 63(63), 101673. doi:10.1016/j.tele.2021.101673.

[96] Faqih, K. M. S., \& Jaradat, M. I. R. M. (2021). Integrating TTF and UTAUT2 theories to investigate the adoption of augmented reality technology in education: Perspective from a developing country. Technology in Society, 67(67), 101787. doi:10.1016/j.techsoc.2021.101787.

[97] Qasem, Z. (2021). The effect of positive TRI traits on centennials adoption of try-on technology in the context of E-fashion retailing. International Journal of Information Management, 56(56), 102254. doi:10.1016/j.ijinfomgt.2020.102254.

[98] Sánchez, M. R., Palos-Sánchez, P. R., \& Velicia-Martin, F. (2021). Eco-friendly performance as a determining factor of the Adoption of Virtual Reality Applications in National Parks. Science of the Total Environment, 798(798), 148990. doi:10.1016/j.scitotenv.2021.148990.

[99] Zanetta, L. D. A., Hakim, M. P., Gastaldi, G. B., Seabra, L. M. A. J., Rolim, P. M., Nascimento, L. G. P., Medeiros, C. O., \& da Cunha, D. T. (2021). The use of food delivery apps during the COVID-19 pandemic in Brazil: The role of solidarity, perceived risk, and regional aspects. Food Research International, 149(149), 110671. doi:10.1016/j.foodres.2021.110671.

[100] Rakshit, S., Islam, N., Mondal, S., \& Paul, T. (2021). Mobile apps for SME business sustainability during COVID-19 and onwards. Journal of Business Research, 135(135), 28-39. doi:10.1016/j.jbusres.2021.06.005. 